\title{
Tooth Surface Configurations Caused by the Errors in Hobs and Hobbing Machines*
}

\author{
Yoji UMEZAKI**, Yasutsune ARIURA** \\ Taku UENO*** and Kazuhide NAGAO**
}

\begin{abstract}
Estimation of the errors of a hob and a hobbing machine is necessary in order to improve the hobbing accuracy. This paper focuses on the configurations remaining on the tooth surfaces of hobbed gears, and illustrates analytically the tooth surface configurations caused by the errors of the hob and the hobbing machine. The errors of hobs concerned are the lead variation and the eccentricity, while the errors of the hobbing machine include the variation of the rotational center and the rotational irregularity of the table. The above-mentioned hobbing errors are closely related to the tooth surface configurations, and particularly, the feed marks express the characteristics of the tooth surfaces very well. As a result of the investigation on the tooth surface configurations and the formation mechanism of the feed marks, it is possible to estimate the hobbing errors by the calculated tooth surface configurations of hobbed gears.
\end{abstract}

Key Words: Gear, Cutting, Hobbing, Tooth Surface Configuration, Feed Mark, Tooth Surface, Hob Accuracy, Gear Accuracy

\section{Introduction}

The improvement of tooth profiles and tooth traces of hobbed gears is important, particularly in the case of gears which are used in the as-hobbed condition and/or without any subsequent finishing. It is necessary to know the hobbing errors, which in this paper refer to the errors of the hob and the hobbing machine. in order to improve the accuracy of the hobbed gears. The hobbing errors which affect the gear accuracy can be ascertained from close investigation of the tooth profiles and tooth traces ${ }^{(1)}$. However, to enable recognition of the hobbing errors via observation of the tooth surface configurations, improvement of the hobbing accuracy, particularly in the manufacturing stage, is imperative.

* Received 19th June, 1989. Paper No. 88-0694A, $-0965 \mathrm{~A}$

** Faculty of Engineering, Kyushu University, 8-10-1 Hakozaki, Higashiku, Fukuoka, 812, Japan

* * Faculty of Engineering, Kyushu Industrial University, 2-3-1 Matsukadai, Higashiku, Fukuoka, 813, Japan
This paper focuses on the configurations remaining on the tooth surfaces of hobbed gears; the tooth surface configurations caused by the errors of the hob and the hobbing machine are investigated analytically. It is very unfortunate that each hobbing error which affects the tooth surface configurations is shown only through experimentation ${ }^{(2)(3)}$, because various hobbing errors affect the finished surfaces in a complicated manner. In this paper, the tooth surface configurations generated with each hob tooth are analyzed numerically in various hobbing conditions including the hobbing errors, and the relation between the tooth surface configurations and the hobbing error is investigated in detail.

\section{Numerical Analysis of the Tooth Surface} Configurations Generated with Hob Teeth

The numerical analysis method of the tooth spaces of hobbed gears ${ }^{(4)}$ is used to obtain the tooth surface configurations. In this method, the length cut with each hob tooth during passing through a number of segments which are provided in the tooth space is calculated. In this way the coordinates conversion of the hob tooth is introduced under the same conditions 
as the hobbing errors. Figure 1 shows the coordinates of the gear $X_{g}-Y_{g}-Z_{g}$, the tooth space $X_{s}-Y_{s}-Z_{s}$ and the group of line segments. The tooth surface configurations are illustrated to develop a bilateral tooth surface in the tooth space coordinates $X_{s^{-}} Y_{s^{-}}$ $Z_{s .}$

Figure 2 shows an example of the calculation of the tooth surface configurations. The regions of the segments cut with three hob teeth are placed one above the other. One part of the hobbed tooth space remains as a generated tooth surface when the hob is fed vertically after one revolution of the gear. This analysis method is able to improve the accuracy of the calculation with increasing the number of line segments; however the number of calculations increases. In this paper, 150 line segments in the tooth space are provided at intervals of $0.15 \mathrm{~mm}$ along the tooth trace. The analysis of the tooth surface configurations caused by the hobbing errors given in Table 1 is

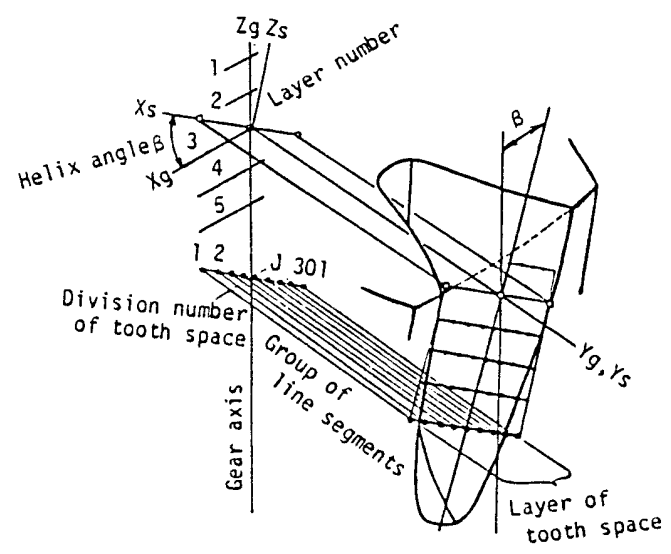

Fig. 1 The coordinates of gear and tooth space and the group of line segments in the numerical analysis ${ }^{(4)}$

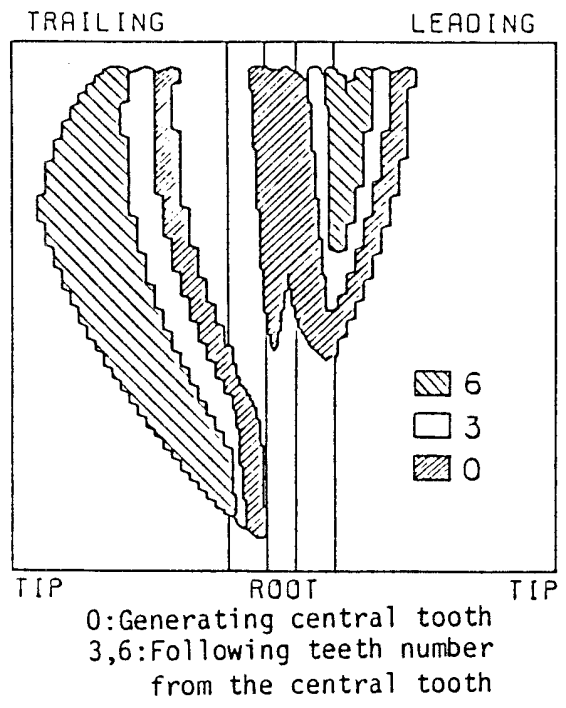

Fig. 2 The overlapping cutting zones carried out using single-thread and triple-thread hobs as an example of multiple-thread hobs.

\section{Comparison of Actual Tooth Surface Configurations with Calculated Ones}

Hobbing experiments were performed using the triple-thread hob B and gears I and II shown in Table 2. The hobbing conditions are given in Table 3. The applicability of this analysis method is investigated by comparing the tooth surface configurations of the hobbed gear with the calculated ones.

Figure 3 shows the photographs of tooth surfaces after hobbing. The feed marks on gear I are linear on the tooth profile at regular intervals along the tooth trace, in spite of the large eccentricity of the hob. On gear II, the feed marks appear to wind around the tooth profile at irregular intervals on the tooth trace.

Figure 4 is an illustration of the tooth surface configurations which are calculated under consideration of the lead variation and eccentricity of the hob. These calculated tooth surface configurations closely resemble those in the hobbing test. There are a few differences in the intervals of the feed marks between the measured and the calculated values, as shown in Fig. 5.

Table 1 The errors of the hob and hobbing machine

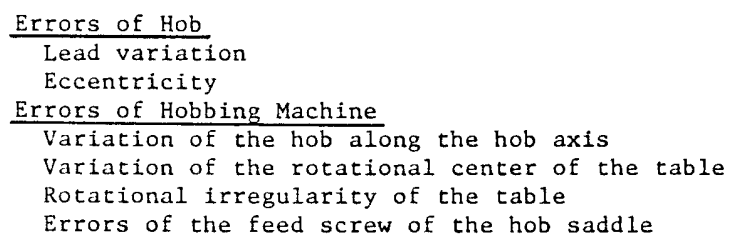

Table 2 Specifications of hobs and gears and cutting conditions

\begin{tabular}{|c|c|c|c|c|c|}
\hline HODS & $\bar{A}$ & B & Gears & II & in \\
\hline $\begin{array}{l}\text { Module } \\
\text { Pressure angle } \\
\text { Lead angle } \\
\text { Outside dia. } \\
\text { No. of threads } \\
\text { No. of gashes } \\
\text { Rake angle }\end{array}$ & $\begin{array}{l}2^{\circ} 22^{\prime} \\
480 \\
1, R H \\
12 \\
\text { stra }\end{array}$ & $\begin{array}{l}5^{\circ} \\
5^{\circ} 371 \\
\phi 100 \\
3,1 \mathrm{RH} \\
14 \\
\text { ight } \\
0^{\circ}\end{array}$ & $\begin{array}{l}\text { Module } \\
\text { Pressure angle } \\
\text { Helix angle } \\
\text { No. of teeth } \\
\text { P.C D D } \\
\text { Tooth profile }\end{array}$ & \begin{tabular}{|r|r|} 
& 3 \\
$40^{\circ}$ & $20^{\circ}$ \\
42 & 44 \\
$\phi 126$ & $\$ 132$ \\
full depth
\end{tabular} & $\begin{array}{c}10^{\circ} \mathrm{RH} \\
35 \\
\$ 106.6 \\
\text { tooth }\end{array}$ \\
\hline
\end{tabular}

Table 3 Cutting conditions in triple-thread hobbing

Cutting conditions

Cutting speed $=20 \mathrm{~m} / \mathrm{min}$, Feed $=2.47 \mathrm{~mm} / \mathrm{rev}$., Conventional Eccentricity

\begin{tabular}{c|c|cc} 
& \multicolumn{3}{|c}{ Hobbing of } \\
& gear I & gear II \\
\hline A & $20 \mu \mathrm{m}$ & $56 \mu \mathrm{m}$ \\
B & $30 \mu \mathrm{m}$ & $56 \mu \mathrm{m}$ \\
\hline
\end{tabular}

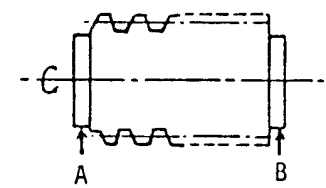

Series III, Vol. 32, No. 4, 1989 


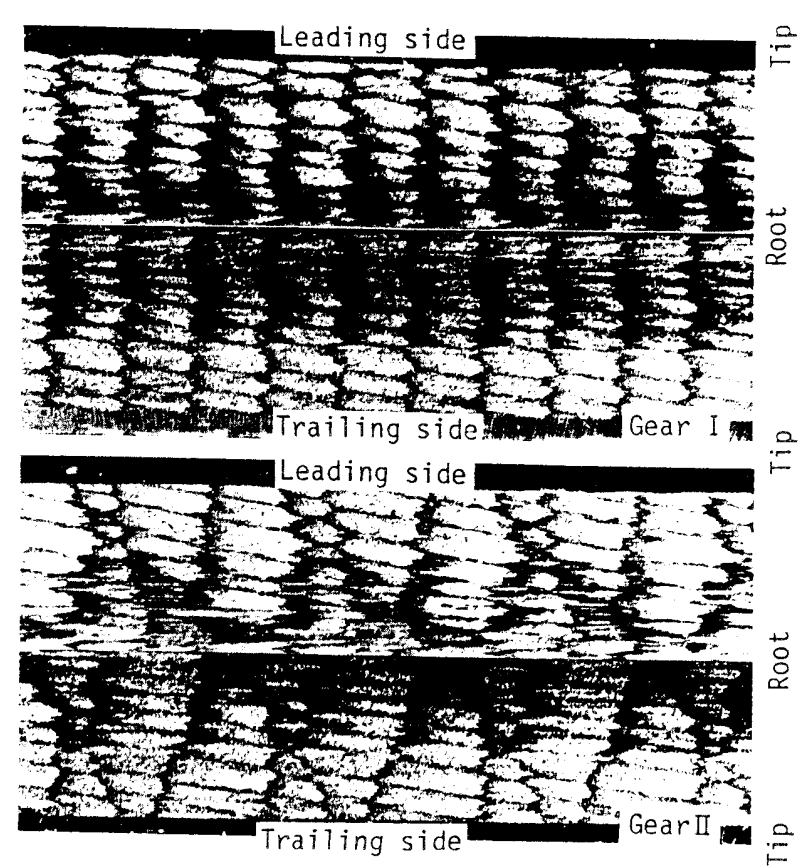

Fig. 3 The tooth surfaces in triple-thread hobbing
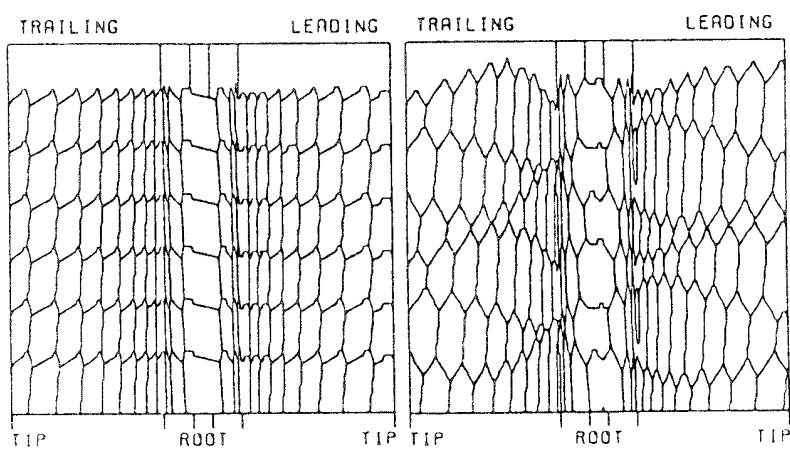

The case in which the no. The case in which the no. of reeth is divisible of reeth is indivisible by the no. of threads by the no. of threads

Fig. 4 The tooth surface configurations in triple-thread hobbing by the numerical analysis
These results show that the analysis method is sufficiently accurate, and therefore it is possible to estimate the hobbing errors from the tooth surface configurations.

\section{Relationship Among Hobbing Errors, Tooth Surface Configurations and Feed Marks}

\section{1 Effect of the lead variation of a hob}

The lead variation is treated as a periodical error in these analyses.

(a) Single-thread hobbing: Figure 6(a) shows the calculated tooth surface configurations in hobbing with hob A and gear I shown in Table 2 with the lead variation measuring $6 \mu \mathrm{m}$. The region generated by hob teeth is irregular in size, though the feed marks lie in a linear arrangement at regular intervals. The width of each cutting region remaining on the tooth surface normally becomes small from tip to root, but the wide portion remains at the root in the case of the hob with the lead variation error, as a result the tooth surface configurations differ from the normal case.

(b) Triple-thread hobbing: The analysis is carried out on hob $\mathrm{B}$ and gears I and II. In the multiple-

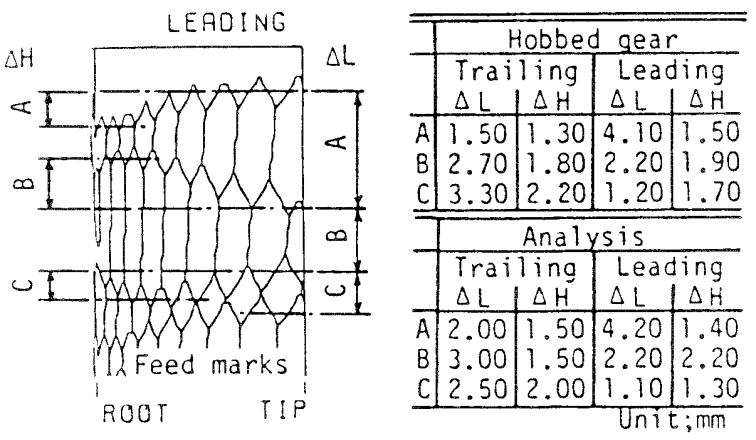

Fig. 5 Comparison of the measured values with the calculated ones in the interval of the feed mark

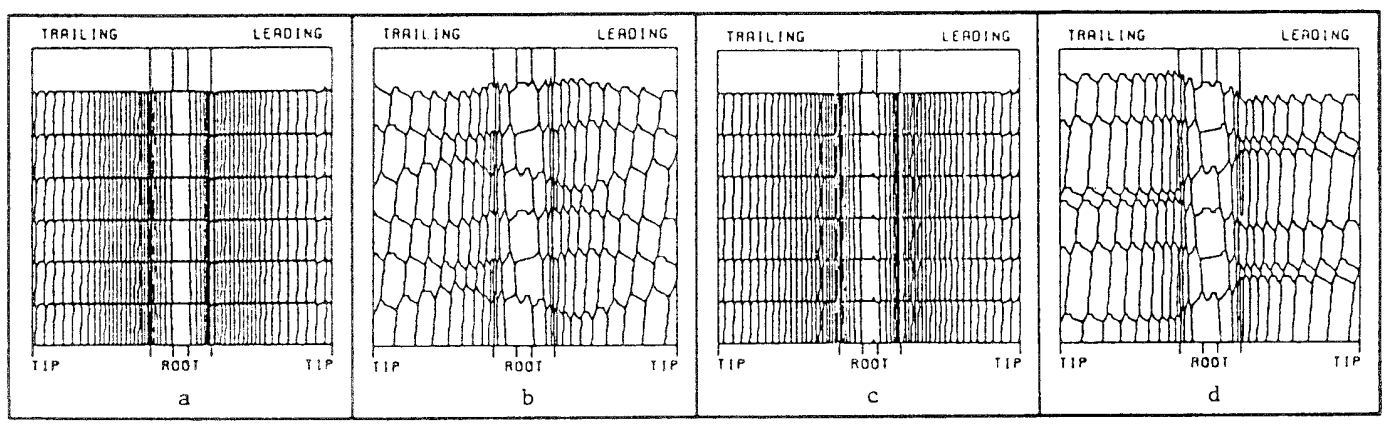

These configurations are calculated under the conditions with the followingerrors, respectively.

a: The lead variation of a single-thread hob

$b$ : The lead variation of a triple-thread hob in the case in which

the number of teeth is indivisible by the number of threads

$c$ : The eccentricity of a single-thread hob

d: The eccentricity of a triple-thread hob in the case in which

the number of teeth is indivisible by the number of threads

Fig. 6 The calculated tooth surface configurations 
thread hobbing, the method of cutting the tooth spaces differs depending on whether the number of teeth is divisible by the number of threads. In the case in which the number of teeth is divisible by the number of threads, the hob teeth on a certain thread generate fixed gear teeth, while in the case in which the number of teeth is indivisible by the number of threads, the hob teeth on the separate thread work on fixed gear teeth alternately.

Figure 6(b) shows the calculated tooth surface configuration of gear II cut with the hob shown in Fig. 7 having a lead variation of $6 \mu \mathrm{m}$. The tooth surfaces of gear II are generated by the first, third and second threads, and the feed marks indicate large winding. The tooth surface configurations of gear I with the aliquot number of teeth by the number of threads are similar to those in single-thread hobbing except that the working teeth are very small in number.

\section{2 Effect of the hob eccentricity}

(a) Single-thread hobbing: Figure 6(c) illustrates the tooth surface configurations of gear I cut with hob A with the eccentricity of $50 \mu \mathrm{m}$ at opposite ends of both hubs of the hob. These tooth surface configurations vary only slightly compared with those of normal hobbing with no errors, and the feed marks are linear on the tooth profile at regular intervals along the tooth trace.

(b) Triple-thread hobbing: The tooth surface configurations of gears I and II cut with hob B are calculated under the same conditions as the above single-thread hobbing. The tooth surface configurations of gear I are similar to those of the single-thread hobbing, and the feed marks lie in a linear arrangement at regular intervals.

Figure 6(d) shows an illustration of the tooth surface configuration of gear II. The tooth surface configurations differ in size per revolution of the gear, and the feed marks lie in a linear arrangement at irregular intervals.

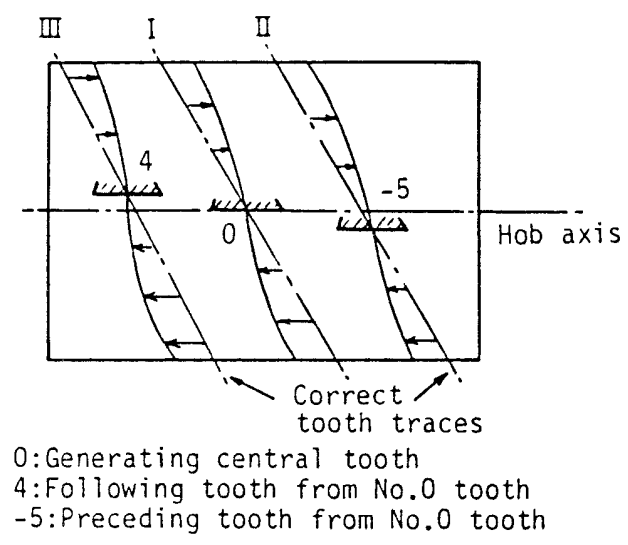

Fig. 7 The lead variation of a triple-thread hob
The analysis of the tooth surface configuration is also carried out according to the effect of the flute spacing error of a hob. As a result, only small changes in the cutting zone are seen on the tooth surface configurations, and the flute spacing error hardly affects the errors of feed marks. This flute spacing error of the hob has the same influence as that of the lead variation of the hob on the tooth surface configurations, because the lead variation is also produced when the flute spacing error appears in the regrinding of the hob teeth.

These results show that the hob errors have much influence on the tooth surface configurations when the number of teeth is divisible by the number of threads in multiple-thread hobbing.

In the errors induced in a hobbing machine, the periodical errors per revolution of the hob which arise from the intermittent cutting force in hobbing and the errors during a long period which arise from the bearing errors in the table and the dividing system of the hobbing machine are analyzed.

\section{3 Effect of the deviation of a hob along the hob axis}

Figure 8 (a) shows the tooth surface configurations of gear I cut with hob A under the condition of the deviation of the hob along the hob axis with $40 \mu \mathrm{m}$ in amplitude of vibration at the period of one revolution of the hob. This deviation of the hob has much influence on the tooth surface configurations, but the feed marks do not wind.

Figure $8(\mathrm{~b})$ shows the tooth surface configurations of helical gear III cut with hob A with the deviation of the hob along the hob axis with $20 \mu \mathrm{m}$ in amplitude at the period of one revolution of the hob. The width of the generated surface with each hob tooth varies largely, and the feed marks wind on the tooth profile at regular intervals along the tooth trace.

\subsection{Effect of the variation of the rotational} center of the table

The center of rotation of the table changes with each revolution of the table as a result of errors caused by insufficient bearings in the table. Although the variation of the table center occurs simultaneously in the direction of the hob axis and the common normal to the hob axis from the gear axis, this paper analyzes its variation in a separate direction.

Figure 8 (c) shows the tooth surface configurations of gear I cut with hob A while the table is vibrated along the hob axis with $20 \mu \mathrm{m}$ amplitude at the period of six revolutions. The feed marks are linear on the tooth profile at different intervals on both tooth surfaces.

Figure 8 ( d ) shows the tooth surface configurations of gear I cut with hob $\mathrm{A}$ when the 


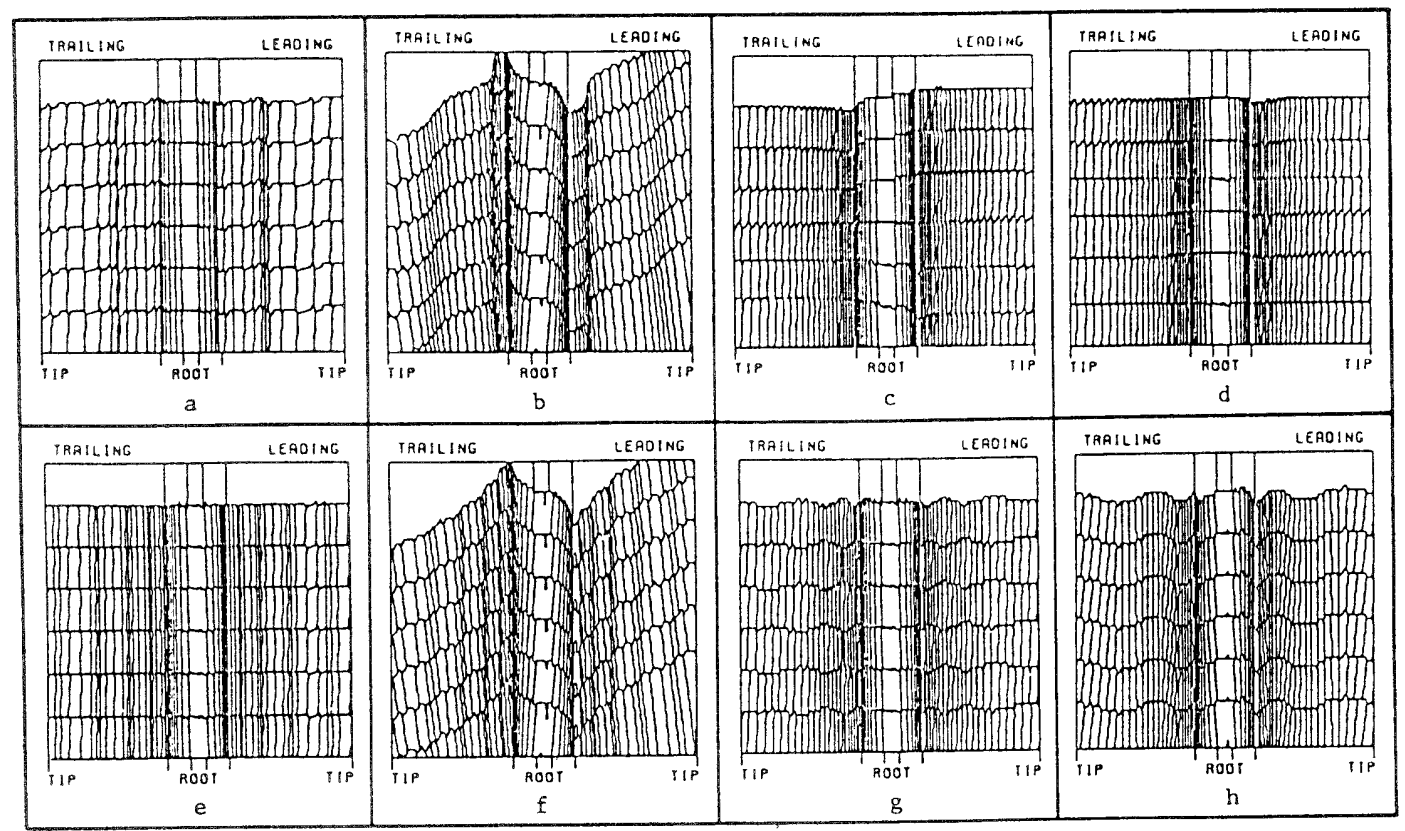

These configurations are calculated under the conditions with the following errors, respectively.
a: The deviation of a hob along the hob axis
. The deviation of a hobalical gear hobbing
. The variation of the rotational center of the table along the hob axis
$d$ : The variation of the rotational center of the table toward the common normal to the hob axis from the gear axis
e: The periodical irregularity of the table rotation during one revolution of the master worm gear
$f:$ The periodical irregularity of the table rotation during one revolution of the master worm gear in the helical gear hobbing
$g:$ The periodical irregularity of the table rotation during
a half revolution of the master worm gear when the phase of the irregularity is inverted per revolution of the table
$h$ : The variation of the hob toward the feed per revolution of the table

Fig. 8 The calculated tooth surface configurations

vibration occurs toward the common normal to the hob axis from the gear axis with $20 \mu \mathrm{m}$ in amplitude at the period of six revolutions of the table. The feed marks are linear on the tooth profile at the same interval on both sides of the tooth surfaces and at different intervals along the tooth trace.

\subsection{Effect of periodical irregularity of the table rotation}

The periodical irregularity occurs in the table rotation owing to errors in the gear train from the hob axis to the master worm axis and the errors in fitting the master worm and wheel gears. The tooth surface configurations arising from the irregularity of the table rotation of 10 seconds in amplitude during one revolution of the master worm gear are analyzed and the results are shown in Figs. $8(\mathrm{e})$ and $8(\mathrm{f})$.

Figure $8(\mathrm{e})$ shows the result of gear I cut with hob A. Each surface generated with hob teeth is irreg. ular in size, and the feed marks are in a linear arrangement.

Figure $8(\mathrm{f})$ shows the case of helical gear III cut with hob A. The feed marks do not wind, and instead lie along the inclined line, since the generating position of the hob tooth does not vary. Each generated surface varies in size along the feed mark.

Next, the tooth surface configurations of gear I cut with hob A are analyzed in Fig. 8(g) under the condition in which the phase of the irregularity of a $10^{-}$ second table rotation during a half revolution of the master worm gear is inverted per revolution of the table. The feed marks wind and repeat the same pattern every two revolutions of the table.

\section{6 Effect of the errors of the feed screw of the hob saddle}

The variation of the feed per revolution of the table or the hob occurs owing to errors of the feed screw such as lead variation as well as errors occurring in fitting the feed screw.

Figure $8(\mathrm{~h})$ illustrates the tooth surface configurations when the variation of the feed is 0.4 $\mathrm{mm}$ in amplitude at the period of one revolution of the hob during hobbing of gear I with hob A. The winding of the feed marks produces the same pattern with each revolution of the table. 
Next, the variation of the feed per revolution of the table is calculated. As a result, the feed marks do not wind on the tooth profile and show different intervals along the tooth trace. The amount of change of the interval is the same as that of the change of feed. In any case, it seems that the errors of the feed screw hardly affect the tooth surface configurations in the hobbing machine with high rigidity, because a large change of the feed marks along the tooth trace is accompanied by a large displacement of the feed screw.

5. The Mechanism of the Formation of Feed Mark Errors, and Comparison of the Feed Marks Obtained by the Numerical Analysis with Those on Actual Hobbed Gears

Feed marks in gear hobbing occur as intersections when the cutting zones with hob teeth meet during each revolution of the table. As the generated surfaces with each hob tooth vary in size owing to the hobbing errors, the length of the intersections vary, resulting in a change in the feed marks. In this section, the mechanism of the formation of feed mark errors is considered and its relation to the hobbing errors is investigated. The figure of the feed marks is classified roughly according to the following three points.

(1) random disorder and irregular shape (ref., Fig. 9) ;

(2) linear shape on a tooth profile at different intervals along the tooth trace per revolution of the

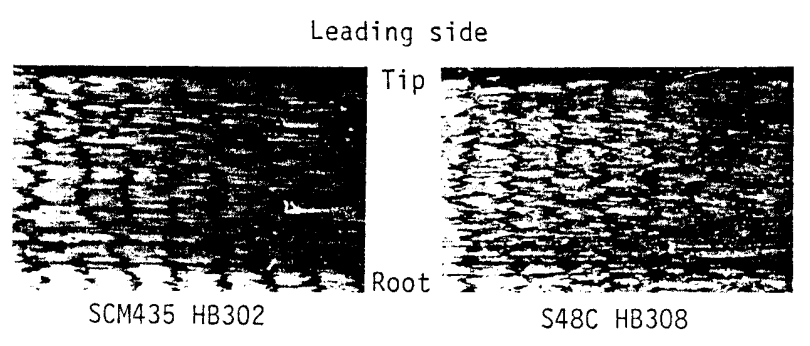

Fig. 9 The tooth surfaces of hobbed gears ( $\mathrm{m} 3$, 1-thread hob)

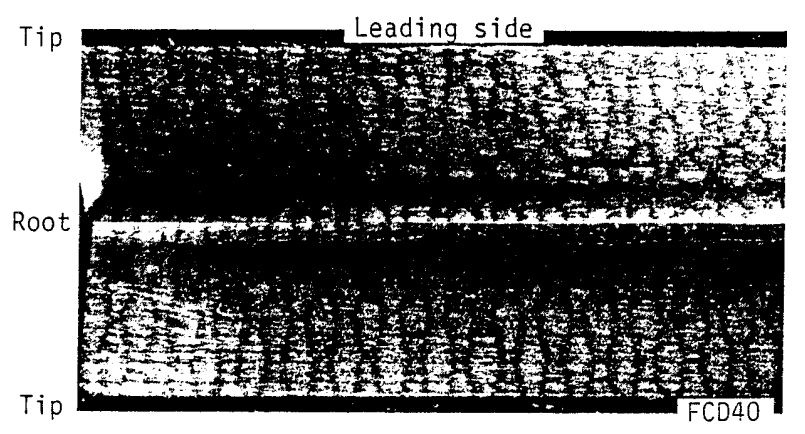

Fig. 10 The tooth surfaces of a hobbed gear (m6, 1thread hob) table (ref., Fig. 10);

(3) winding shape on a tooth profile showing a regular pattern along the tooth trace (ref., Fig. 11).

Figures 9, 10 and 11 show examples of actual hobbed gears for each case.

\subsection{Random disorder and irregularly shaped feed marks}

Figure 9 shows the tooth surfaces of steel gears hobbed using a high-speed steel hob under rough cutting conditions. The tooth surfaces become rough, and the feed marks are disordered because of scratches caused by overcutting of built - up edges attached to the hob teeth and biting scratches of chips $^{(5)}$. The low rigidity of the hobbing machine and the irregular generating motion by the vibration arising from the large gap near the hob axis cause these feed mark errors.

5. 2 Feed marks at different intervals along the tooth trace

Figure 12 illustrates an arbitrary section of a

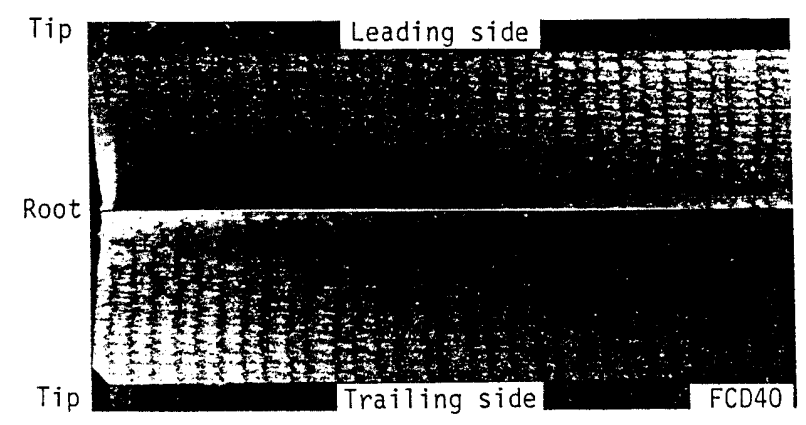

Fig. 11 The tooth surfaces of a hobbed gear (m6.1thread hob)

(a) Change of feed

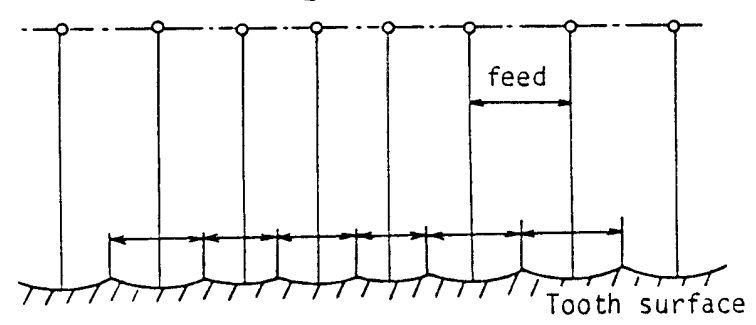

(b) Change of cutting depth

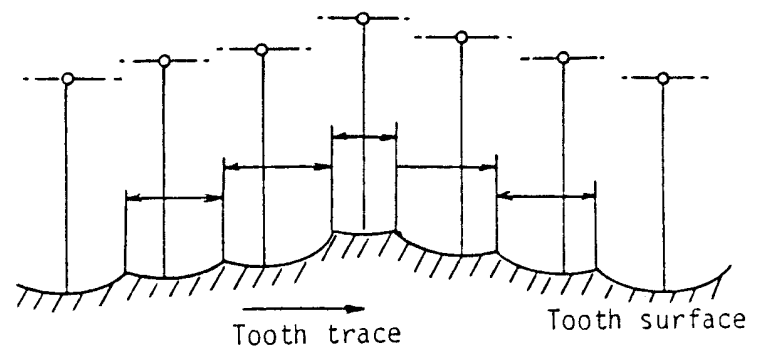

Fig. 12 The mechanism of variation in the feed mark interval 
tooth surface along the tooth trace. Figure $12(\mathrm{a})$ is an illustration of the mechanism whereby the variation of the hob feed appears according to the interval of the feed. In this case, the feed marks vary at the same interval on both sides of the tooth space. The feed mark pattern is mainly caused by the variation of the hob feed arising from the error and eccentricity of the feed screw.

Figure $12(\mathrm{~b})$ shows the case in which the side cutting edge of the hob tooth shifts toward the tooth trace, changing the cutting depth on the tooth surface. The feed marks shown in Fig. 10, an example of spur gear hobbing with a single-thread hob, seem to be caused by the variation of the rotational center of the table, judging from the fact that the interval of the feed marks differs on each side of the tooth space and the same pattern is repeated after a few revolutions of the table. The feed mark error illustrated in Fig. 12 (b) is mainly caused by the variation of the hob along the hob axis after each revolution of the table and the variation of the rotational center of the table and the eccentricity of the multiple-thread hob in hobbing with an aliquant number of teeth by the number of threads.

\section{3 Winding feed marks}

Figure 13 illustrates the locus of side cutting edges in both directions of the tooth trace and the tooth profile. Figure 13(a) shows the normal position of rotational center of the hob. Figure 13(b) shows the variation of the rotational center of each cutting tooth along the feed direction. The feed marks wind in the displacement of the feed in this case, and they appear to wind in a regular pattern when the change of the rotational center of the hob tooth along the feed direction is repeated after each revolution of the table.

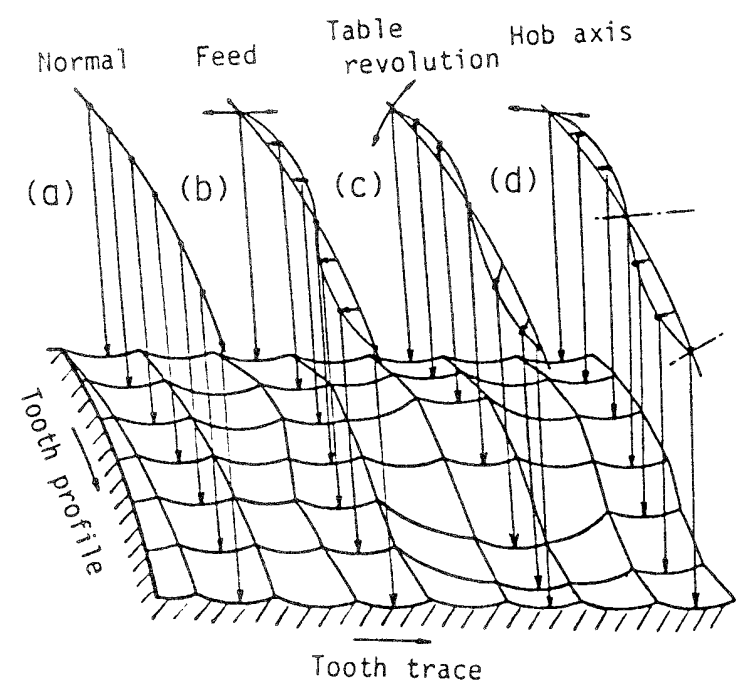

Fig. 13 The mechanism of winding in feed marks
The feed marks illustrated in Fig. 13( $b$ ) seem to be caused by the vibration of the hob in the feed direction owing to the change of the cutting force per revolution of the hob.

Figure 13(c) shows the case of the variation of the cutting depth to the tooth surface with the side cutting tooth. The feed marks will wind if the cutting depth on the tooth surface with each hob tooth varies before and after the table revolution. The causes of this feed mark are the lead variation of the multiplethread hob in hobbing with an aliquant number of teeth by the number of threads and the variation of the table revolution arising from the error in the dividing system of the hobbing machine when the phase of its variation differs at each table revolution.

On the other hand, the feed marks do not wind, as shown in Fig. 14, regardless of the eccentricity of the hob when the phase of the variation of cutting depth is the same before and after the table revolution in Fig. 13( c ). This is because the hob tooth always generates the same position on the tooth surface as the single-thread hobbing.

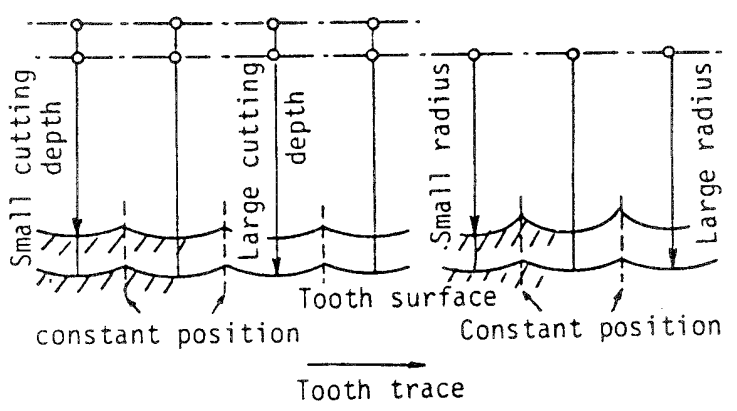

Fig. 14 The mechanism of constant interval of feed marks in the case of different cutting depths with the hob teeth having eccentricity and a different radius

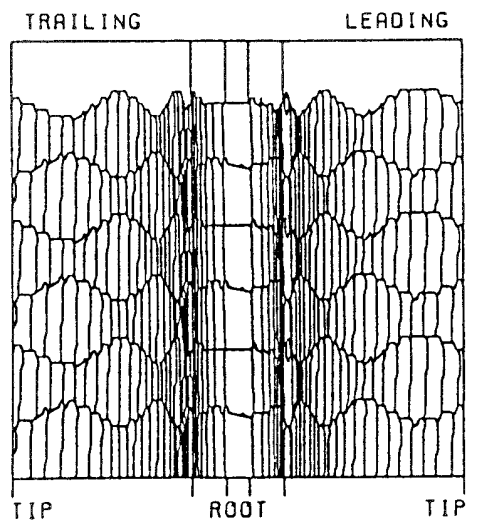

Fig. 15 The calculated tooth surface configurations caused by the rotational irregularity of the table owing to the eccentricity of the indexing gear axis 
Figure 11 shows an example of the tooth surfaces in the single-thread hobbing of the gear with 30 teeth on the hobbing machine with the triple-thread master worm and the wheel gear of 60 teeth. The feed mark repeats the same pattern at every other revolution of the table. The tooth surface configuration is analyzed in Fig. 15 in terms of the vibration of the table revolution of 10 seconds in amplitude, assuming that the irregularity of the rotation at the period after one revolution of one of the gears in the dividing system, with a ratio of 1 to 2 , is transmitted to the master worm gear. Figure 15 clearly indicates the feature of the feed mark shown in Fig. 11. The cause of the feed mark shown in Fig. 15 is the eccentricity of the gear axis in the dividing system, and this is also shown by the measurement of the dividing gears.

Figure 13(d) shows the case of the variation of the hob tooth along the hob axis. Since the generating positions of the tooth profile on the side cutting edges of hob teeth and those on the normal tooth profile vary in this case, the feed marks wind so that they shift from the inclined line in the helical gear hobbing.

The consideration of the formation mechanism of the above feed mark errors suggests the following fundamental causes.

(1) external causes such as built-up edges and chips, except hobbing errors ;

(2) the vibration of the hob toward the feed owing to cutting forces ;

(3) the variation of the feed and the cutting depth

\begin{tabular}{|c|c|c|c|}
\hline Configurations of feed marks & Characteristics & $\begin{array}{l}\text { Causes of feed } \\
\text { mark errors }\end{array}$ & $\begin{array}{l}\text { Errors of hob and } \\
\text { hobbing machine }\end{array}$ \\
\hline 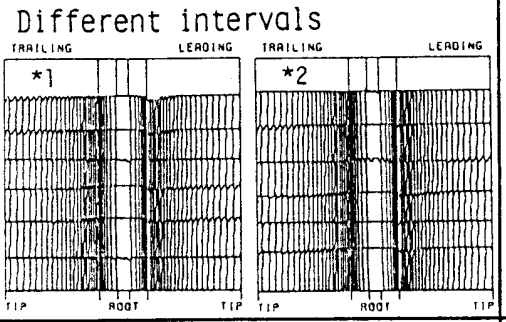 & $\begin{array}{l}\text { *Same intervals on } \\
\text { both sides of the } \\
\text { tooth space }\end{array}$ & $\begin{array}{l}\text { *Variation of the } \\
\text { center distance } \\
\text { between the hob } \\
\text { and the work-gear } \\
\text { *Variation of the } \\
\text { feed }\end{array}$ & $\begin{array}{l}\text { * Lack of rigidity of } \\
\text { the hob saddle } \\
\text { *Variation of the rotational } \\
\text { center of the table }(\star 1) \\
\text { (Insufficient bearings } \\
\text { in the table) } \\
\text { *Directional error of the } \\
\text { feed guide } \\
\text { *Errors, unsteady motion } \\
\text { and eccentricity of the } \\
\text { feed screw }(\star 2)\end{array}$ \\
\hline$\underset{T P}{x}$ & $\begin{array}{l}\text { *Different intervals } \\
\text { on both sides of the } \\
\text { tooth space } \\
\text { (In many cases, these } \\
\text { intervals are re- } \\
\text { peated after a few } \\
\text { revolutions of work) }\end{array}$ & $\begin{array}{l}\text { *Variation of cutting } \\
\text { depth to the tooth } \\
\text { surface }\end{array}$ & $\begin{array}{l}\text { *Eccentricity of the multi- } \\
\text { thread hob in the case of } \\
\text { the aliquant number of } \\
\text { teeth by the number of } \\
\text { threads }(\star 3) \\
\text { *Variation of the rotational } \\
\text { center of the table }(* 4) \\
\text { (Insufficient bearings) } \\
\text { *Directional error of the } \\
\text { feed guide }\end{array}$ \\
\hline 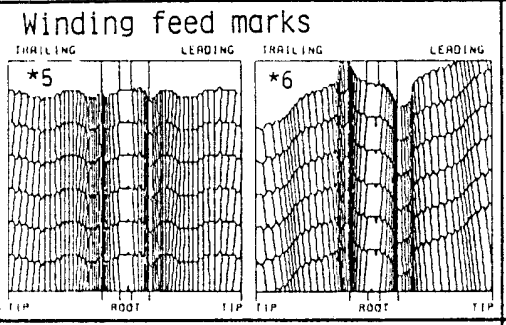 & $\begin{array}{l}\text { * Repeat of same feed } \\
\text { marks }\end{array}$ & $\begin{array}{l}\text { *Variation of the } \\
\text { feed } \\
\star \text { Deviation of the hob } \\
\text { along the hob axis } \\
\text { in the helical gear } \\
\text { hobbing }\end{array}$ & $\begin{array}{l}\text { *Unsteady motion of } \\
\text { the feed screw }(* 5) \\
\text { * Unsteady motion of the } \\
\text { hob arbor by hob thrust } \\
\text { force }(* 6) \\
\text { (Lack of rigidity of the } \\
\text { hob saddle and insuffi- } \\
\text { cient bearings near the } \\
\text { hob axis) }\end{array}$ \\
\hline C.m & $\begin{array}{l}\text { *Different configu- } \\
\text { rations per } \\
\text { revolution of the } \\
\text { table } \\
\text { * Repeat of these feed } \\
\text { marks after a few } \\
\text { revolutions of the } \\
\text { table }\end{array}$ & $\begin{array}{l}\text { *Variation of table } \\
\text { revolution } \\
\text { (The phase of the } \\
\text { variation differs } \\
\text { per revolution } \\
\text { of the table) }\end{array}$ & $\begin{array}{l}\text { *Lead variation of the multi- } \\
\text { thread hob in the case of } \\
\text { the aliquant number of } \\
\text { teeth by the number of hob } \\
\text { threads }(\star 7) \\
\star \text { Errors of the master worm } \\
\text { gear, such as eccentricity } \\
\text { and deviation of the worm } \\
\text { gear along the worm axis } \\
\star \text { Errors and eccentricity of } \\
\text { indexing gears of the } \\
\text { hobbing machine }(\star 8) \\
\end{array}$ \\
\hline $\begin{array}{l}\text { Random disorder and } \\
\text { irregularly shaped } \\
\text { feed marks }\end{array}$ & *Irregularity & $\begin{array}{l}\star 0 \text { vercutting with } \\
\text { built-up edges and } \\
\text { chips } \\
\star \text { Random variation of } \\
\text { generating motion }\end{array}$ & $\begin{array}{l}\text { * Lack of rigidity of the } \\
\text { hobbing machine }\end{array}$ \\
\hline
\end{tabular}

Fig. 16 The relation between the feed marks and the errors of the hob and hobbing machine 
to tooth surfaces that varies with each revolution of the table.

\section{4 Summary of the relationship between the hobbing errors and the feed marks}

The tooth surface configurations arising from the above-mentioned hobbing errors are collected and systematized about the figures of feed marks in Fig. 16. The feed marks are classified roughly into three cases i.e., a linear shape at different intervals along the tooth trace, the winding shape, and the irregular shape. Generally, in the case of the different intervals of feed marks, the relative variation between a hob and work-gear with a long period such as table rotation is one of the causes, while in the case of winding feed marks, the variation with the short period such as rotation of the hob and the master worm gear is another cause.

\section{Conclusions}

Tooth surface configurations caused by the errors in the hob and the hobbing machine are shown by using the numerical analysis method. The tooth surface configurations in actual hobbing tests show that the analysis of the tooth surface configurations is sufficiently accurate. The relation between the hob errors and the tooth surface configurations is investigated, particularly on the feed mark pattern, and it is summarized in Fig. 16. The feed marks are influenced by slight errors in generation among the rotation of the hob and table and the feed motion. From the result of consideration and investigation on the tooth surface configurations and the formation mechanism of the feed marks, it is possible to estimate the errors of the hob and the hobbing machine by the calculated tooth configurations of hobbed gears.

\section{Acknowledgment}

The authors are much indebted to Mr.S.Murai, the director of Kashifuji Works, Ltd., for help with the experiments.

\section{References}

(1) Ariura, Y., Chiu, H. and Umezaki, Y., Improvement of Gear Accuracy in Gear Hobbing ( 1 st Report, A Numerical Analysis of Tooth Profile Errors), JSME Int. J., Vol. 30, No. 259 (1987), p. 168.

(2) Ainoura, M., Yokote, T. and Yonekura, M., Prep. of Jpn. Soc. Mech. Eng. (in Japanese). No. 725-2 (1972), p. 203.

(3) Ainoura, M., Yokote, T. and Yonekura, M., Prep. of Jpn. Soc. Mech. Eng. (in Japanese), No. 730-4 (1973), p. 53.

(4) Terashima, K. and Ueno, T., Numerical Analysis of Hobbing in Unfinished Space, Bull. JSME, Vol. 21. No. 155 (1978), p. 907.

(5) Umezaki, Y., Ueno, T., Kasai, S. and Tin Maung Oo, Fundamental Research on Hobbed-Gear Tooth surface Roughness - Influence of the BuiltUp Edge -, Bull. JSME, Vol. 25, No. 199 (1982), p. 110. 